\title{
Entendendo o papel de marcadores biológicos no câncer de pulmão*
}

\author{
VERA LUIZA CAPELOZZI ${ }^{1}$
}

Marcadores biológicos são componentes celulares, estruturais e bioquímicos, que podem definir alterações celulares e moleculares tanto em células normais quanto aquelas associadas a transformação maligna. Podem ser de dois tipos: 1) marcadores intermediários, que medem alterações celulares e moleculares antes do aparecimento da malignidade; 2) marcadores diagnósticos, presentes em associação com a malignidade. O processo de identificação $e$ validação para uso clínico do marcador tem diversas etapas: identificação inicial feita em linhagens celulares do tumor em questão; teste do marcador em tecido proveniente de biópsias de pacientes com diagnóstico estabelecido do tumor em questão; teste em biópsias de tecidos normais e com processo inflamatório;

teste em escarro, sangue ou urina para validação como teste não-invasivo que possa ser usado em

população de alto risco. Marcadores biológicos diagnósticos sorológicos e histológicos são componentes celulares, estruturais e bioquímicos, presentes não só em células tumorais como também em células normais, que podem ser medidos quantitativamente por métodos bioquímicos,

imunológicos e moleculares nos fluidos ou nos tecidos corporais, respectivamente, associados a neoplasias e possivelmente ao órgão de origem da neoplasia. Marcadores biológicos são estudados em diferentes neoplasias primárias, porém poucos tiveram seu valor clínico definido. O papel dos marcadores biológicos em câncer de pulmão ainda é incerto, pois apenas um pequeno número de marcadores foi avaliado de maneira adequada. O objetivo deste trabalho é entender o papel dos marcadores biológicos sorológicos e diagnósticos no prognóstico e sobrevida de pacientes com câncer de pulmão baseado em uma coletânea de trabalhos realizada pela autora. Apresenta-se também uma perspectiva futura para a detecção precoce do câncer de pulmão baseada no papel dos marcadores biológicos intermediários. (J Pneumol 2001;27(6):321-328)

\section{Understanding the role of biological markers in lung cancer}

Biological markers are cellular, structural and biochemical components that can define cellular as well as molecular changes in both normal and neoplastic cells. There are two types of biological markers: 1) intermediate markers that evaluate cellular and molecular alterations before malignancy occurs; and 2) diagnostic markers, present in association with malignancy. The identification and validation of biological markers for clinical use are performed in stages:

- initial identification in cell cultures of the tumor; - testing of the marker in tissues obtained in biopsies of patients with an established diagnosis of the tumor; - testing of biopsies of normal tissues and tissues with an inflammatory process; - sputum, blood or urine tests for validation as a non-invasive test that can be used in high-risk populations. Sorologic and histopathologic biological markers are cellular, structural and biochemical components found in both normal and neoplastic cells that can be quantitatively assessed by biochemical, immunological and molecular methods in the body fluids or tissues, respectively, and may be associated with malignancies and, possibly, with the neoplastic organ. Biological markers are studied in diverse primary neoplasms.

However, few of them proved to be clinically valuable. The role of biological markers in lung cancer patients remains unclear because only a small number of markers has been properly

* Trabalho realizado no Departamento de Patologia da Faculdade de Medicina da Universidade de São Paulo, São Paulo, SP. Apoio Científico: Fapesp - Fundação de Amparo à Pesquisa do Estado de São Paulo; LIM05-HC-FMUSP - Laboratório de Investigação Médica, Hospital das Clínicas da Faculdade de Medicina da Universidade de São Paulo; CNPq - Conselho Nacional de Desenvolvimento Científico e Tecnológico.

1. Professora Associada.
Endereço para correspondência - Vera Luiza Capelozzi, Faculdade de Medicina da USP, Av. Dr. Arnaldo, 455, 1o and., sala 1.143 - 01246903 - São Paulo, SP. Tel. (11) 3066-7427; Fax (11) 5096-0761; Email: vcapelozzi@lim05.fm.usp.br

Recebido para publicação em 20/4/01. Aprovado, após revisão, em 17/5/01. 
assessed. The aim of this paper is to understand the role of sorologic and histologic biological markers in the prognosis and survival of lung cancer patients based on our previous works. Furthermore, we present a future perspective of the early detection of lung cancer on the basis of the role of intermediate biological markers.

Descritores - Marcadores biológicos. Câncer de pulmão. Prognóstico. Sobrevida.

Key words - Biologic markers. Lung cancer. Prognosis. Survival. Morphometric method.

\section{INTRODUÇÃO}

O câncer de pulmão é a segunda neoplasia mais freqüente nos Estados Unidos e representa a principal causa de morte por câncer naquele país(1). Estimou-se que nos Estados Unidos seriam diagnosticados 171.500 casos novos e ocorreriam 160.000 mortes por câncer de pulmão no ano 2000. Nesse mesmo país o câncer de pulmão é responsável por $14 \%$ de todos casos novos de câncer no homem, mais freqüente depois do câncer de próstata, que representa $36 \%$. Entre as mulheres também ocupa a segunda posição em incidência, $13 \%$ de todos casos novos, precedido pelo câncer de mama, que é responsável por $32 \%$. O carcinoma de pulmão é a principal causa de morte tanto no homem (33\% de todas as mortes por câncer) quanto na mulher ( $24 \%$ de todas as mortes por câncer).

No Brasil, segundo dados recentes do Ministério da Saúde ${ }^{(2)}$, estimou-se a ocorrência de 20.000 casos novos de câncer do pulmão no ano de 1998, sendo o quarto sítio mais freqüente, precedido pelo câncer de mama, colo uterino e estômago. Nos homens é o câncer mais freqüente (15.040 casos novos), sendo também o mais letal, com 9.400 mortes no ano de 1998. Entre as mulheres, o câncer de pulmão representou o quinto sítio mais comum, com 4.960 casos novos e 3.300 mortes no ano de 1998.

O carcinoma broncogênico vem representando um grande desafio para os oncologistas, uma vez que, apesar de todos os avanços diagnósticos e terapêuticos, a taxa de sobrevida global em cinco anos permanece inalterada em $13 \%$ ao longo das últimas décadas ${ }^{(3)}$.

Histológica e clinicamente, os carcinomas broncogênicos são classificados em carcinoma de pulmão de células não-pequenas (CPCNP) e carcinoma de pulmão de células pequenas (CPCP). O CPCNP é o mais freqüente, 75 a $80 \%$ de todos $\operatorname{casos}^{(3)}$; nestes pacientes o estadiamento clínico é fundamental para estabelecer a estratégia terapêutica.

Em geral, o tratamento loco-regional (cirurgia ou radioterapia) é recomendado para os pacientes com doença localizada. Os pacientes com CPCNP metastático são submetidos a tratamento quimioterápico. A base do tratamento dos pacientes com СРCP é a quimioterapia ${ }^{(4)}$.
Siglas e abreviaturas utilizadas neste trabalho

CPCNP - Carcinoma de pulmão de células não-pequenas

CPCP - Carcinoma de pulmão de células pequenas

CEA - Antígeno carcino-embrionário

SCC - Carcinoma de células pequenas

NORs - Regiões organizadoras do nucléolo

SKY - Cariótipo espectral

A maioria dos pacientes com CPCNP apresenta doença em estádios avançados na ocasião do diagnóstico, sendo isso um dos motivos da sua alta taxa de mortalidade. Estima-se que, no momento do diagnóstico de CPCNP, $20 \%$ dos pacientes têm doença localizada, $25 \%$ têm extensão da neoplasia para os linfonodos mediastinais e $55 \%$ já apresentam metástases a distância ${ }^{(5)}$.

Nos estádios mais precoces a ressecção cirúrgica representa a chance real de cura ${ }^{(6)}$; entretanto, mesmo no estádio clínico IA (T1NOM0), cerca de 30 a $40 \%$ dos pacientes morrerão em conseqüência da progressão da neoplasia $^{(6-8)}$, principalmente à custa de recidiva sistêmica. $\mathrm{A}$ administração de terapêutica adjuvante para esses pacientes ainda não mostrou claro benefício na melhora da sobrevida $^{(9)}$. Por esse motivo, a identificação de fatores prognósticos vem sendo objeto de estudo de diferentes pesquisadores, com a finalidade de selecionar os pacientes com maior risco de recidiva. Esses pacientes selecionados teriam benefício potencial com terapêuticas adjuvantes, que visam evitar a recidiva da neoplasia e a sua evolução fatal.

Várias características clínicas, patológicas e moleculares vêm sendo estudadas e apontadas como fatores determinantes da sobrevida nos pacientes com $\mathrm{CPCNP}^{(6,10)}$. Os fatores mais importantes para avaliação prognóstica são o performance status, o estadiamento clínico e a perda de peso ${ }^{(3,6)}$. Essas características são utilizadas como parâmetros para avaliar o impacto na sobrevida dos novos fatores prognósticos pesquisados. Dentre esses, a concentração sérica dos marcadores tumorais vem sendo estudada nos pacientes com CPCNP(11).

Marcadores biológicos são componentes celulares, estruturais e bioquímicos, presentes não só em células tumorais como também em células normais. Nas células tumorais definem alterações celulares e moleculares associadas a transformação maligna. Podem ser de dois tipos: 1) marcadores intermediários, que medem alterações celulares e moleculares antes do aparecimento da malignidade; 2) marcadores diagnósticos, presentes em associação com a malignidade ${ }^{(12)}$. O processo de identifi- 
cação e validação para uso clínico do marcador tem diversas etapas:

- identificação inicial feita em linhagens celulares do tumor em questão;

- teste do marcador em tecido proveniente de biópsias de pacientes com diagnóstico estabelecido do tumor em questão;

- teste em biópsias de tecidos normais e com processo inflamatório;

- teste em escarro, sangue ou urina para validação como teste não-invasivo que possa ser usado em população de alto risco.

\section{MARCADORES BIOLÓGICOS DIAGNÓSTICOS - CÂNCER ESTABELECIDO}

Marcadores biológicos diagnósticos são substâncias e estruturas, tais como o núcleo, a angiogênese, os microvilos, os microácinos (ver marcadores biológicos diagnósticos histológicos citados logo a seguir), que podem ser medidos quantitativamente por métodos bioquímicos, imunológicos, morfométricos, ultra-estruturais e moleculares nos fluidos ou nos tecidos corporais, associados a neoplasias e possivelmente ao órgão de origem no caso de eventual neoplasia ${ }^{(12)}$. Nas últimas décadas, várias proteínas e pequenos peptídeos têm sido identificados como produtos de secreção de diferentes neoplasias sólidas ${ }^{(13)}$, podendo ser utilizados como marcadores tumorais diagnósticos.

Em 1848, Bence Jones descreveu a proteína do mieloma múltiplo, primeira substância empregada clinicamente como marcador tumoral ${ }^{(13)}$. Desde estão, várias outras substâncias vêm sendo pesquisadas em neoplasias de diferentes sítios primários, com o objetivo de avaliar a sua aplicação na prática clínica.

Os marcadores biológicos diagnósticos podem ser úteis no manejo clínico dos pacientes com câncer, auxiliando nos processos de diagnóstico, estadiamento, avaliação de resposta terapêutica, detecção de recidivas e prognóstico. Inúmeras substâncias estão sendo continuamente descobertas e algumas, amplamente empregadas na prática diária, apesar de poucas evidências científicas que autorizem a sua aplicação clínica(14).

Em pacientes com câncer de pulmão os marcadores biológicos diagnósticos propriamente ditos não se mostraram úteis como recurso diagnóstico, devido à sua baixa sensibilidade e especificidade. Entretanto, os marcadores biológicos diagnósticos podem ser utilizados para expressar diferentes características biológicas dos carcinomas broncogênicos ${ }^{(15)}$.

\section{Marcadores BIOLÓGICOS DIAGNÓSTICOS SOROLÓGICOS}

Várias substâncias classificadas como marcadores biológicos diagnósticos séricos já foram estudadas em pa- cientes com CPCNP. Os marcadores biológicos diagnósticos séricos mais estudados em pacientes com CPCNP são: CEA (antígeno carcino-embrionário), TPA (antígeno polipeptídeo tecidual), SCC-Ag (antígeno do carcinoma de células escamosas), Chr A (cromogranina A), NSE (enolase neurônio-específica), CYFRA21.1 (fragmentos de citoqueratina medidos no sangue através dos anticorpos monoclonais KS19-1 e BM19-21), NCAM (molécula de adesão celular neural); CPK-BB (creatina fosfoquinase - BB); sIL-2R (receptor de interleucina solúvel-2). As principais aplicações clínicas pesquisadas para esses marcadores são o seu papel no estadiamento e na avaliação prognóstica.

Poucos pesquisadores brasileiros estudaram o papel dos marcadores biológicos séricos em pacientes com carcinoma broncogênico. Em 1992, Takagaki ${ }^{(16)}$ analisou o papel dos marcadores biológicos diagnósticos em 60 pacientes com carcinoma broncogênico. Observou que o CEA foi o marcador mais freqüentemente aumentado nesses pacientes e o CA72.4 o que melhor se correlacionou com a extensão da neoplasia. Em 1999, Gross ${ }^{(17)}$ estudou 103 pacientes com CPCNP e observou que o CYFRA21.1 foi o marcador mais elevado (55\%), seguido pelo CA72.4 (50\%), CEA (44,4\%), enolase neurônio-específica $(35,7 \%)$, CA15.3 (31\%) e CA19.9 (14,7\%). Nesse estudo, isoladamente nenhum dos marcadores biológicos diagnósticos teve valor prognóstico independente, porém a associação de marcadores biológicos elevados pode auxiliar na identificação dos pacientes com pior sobrevida.

\section{MARCADORES BIOLÓGICOS DIAGNÓSTICOS HISTOLÓGICOS}

\section{Imunocitoquímica}

Carcinomas de células escamosas demonstram reatividade para queratinas de baixo $e$ alto peso molecular $e$ para involucrina. Imunorreatividade também tem sido constatada para vimentina, antígeno epitelial de membrana (EMA), glóbulos de gordura do leite humano (HMF62), proteína S-100, Leu-M1 e CEA. A mucosa adjacente ao tumor usualmente mostra metaplasia escamosa e carcinoma in situ. Recentemente, presença de HPV foi detectada em $20 \%$ de SqCC e substancialmente maior nos casos mostrando características condilomatosas no epitélio adjacente.

Adenocarcinomas mostram reatividade para queratinas de baixo peso molecular, antígenos de membrana epitelial, CEA e componentes secretórios. A expressão de queratina 7 tem sido tomada como evidência de diferenciação glandular no carcinoma de pulmão. Pode haver em algumas situações co-expressão de queratina $e$ vimentina. Células de Langerhans S-100 positivas são freqüentes no estroma tumoral. Em cerca de metade dos casos há positividade para apoproteínas do surfactante pulmonar, uma característica altamente eficaz no diagnóstico diferencial com outros tipos de carcinoma de pulmão e, mais 
importante, com adenocarcinomas metastáticos. Catepsina $\mathrm{B}$ e componentes da membrana basal são também encontrados. Adenocarcinomas de pulmão mostram ainda consistente expressão de antígenos Lewis $\mathrm{X}$ e $\mathrm{Y}$ dos grupos sanguíneos, característica esta de valor também no diagnóstico diferencial.

Adenocarcinomas metastáticos do trato digestivo (CK20+; CK7-) nos pulmões (CK20-; CK7+) podem ser diferenciados pela expressão de queratinas de baixo peso.

Múltiplos polipeptídeos são produzidos pelo câncer de pulmão, particularmente nos carcinomas de pequenas células (SCC). A Tabela 1 lista os marcadores neuroendócrinos observados em SCC e carcinomas de células nãopequenas (NSCC).

Heterogeneidade de expressão existe. Fenótipo neuroendócrino é tipicamente definido como expressão de dois ou mais marcadores listados na Tabela 1. Por essa definição, $75 \%$ dos SCC e 20 a $25 \%$ dos NSSC têm fenótipo neuroendócrino. Em NSSC, alguns estudos têm mostrado que fenótipo neuroendócrino se associa com melhor resposta à quimioterapia e melhora na sobrevida ${ }^{(18-}$ 20).

Células cancerosas e não-cancerosas do pulmão comumente produzem hormônios peptídeos que podem ter função como mitógenos. Estes incluem GRP (gastrin-releasing peptide), ECG (epidermal growth factor) e IGF (insuline-like growth factor). As células pulmonares cancerosas têm receptores para esses fatores, de forma que esses peptídeos podem funcionar como fatores de crescimento autócrino nas células cancerosas e normais.

\section{Microscopia eletrônica}

Características submicroscópicas têm sido identificadas para distinguir tumores pulmonares ${ }^{(21-23)}$. Dos 41 carcinomas de pulmão considerados carcinomas anaplásicos de grandes células à microscopia de luz, Delmonte Capelozzi et al. ${ }^{(21-23)}$ encontraram 8 (40\%) com ausência de evidencias ultra-estruturais de diferenciação. Os 33 remanescentes mostraram alguma evidência de diferenciação escamosa (desmossomos e tonofilamentos), glandular (mi-

\section{TABELA 1}

Imuno-histoquímica dos marcadores neuroendócrinos em câncer de pulmão

\begin{tabular}{llrl}
\hline \multicolumn{1}{c}{ Marcadores } & \multicolumn{1}{c}{ SCC } & NSSC & \multicolumn{1}{c}{ Referência } \\
\hline L-dopa descarboxilase & $48-82 \%$ & $12-33 \%$ & Gazdar, 1988 ${ }^{(18)}$ \\
Cromogranina-A & $48-93 \%$ & $0-28 \%$ & Graziano, 1989 \\
Enolase & $93-100 \%$ & $27-57 \%$ & Jorgensen, 1990 \\
Bombesina (GRP) & $20-69 \%$ & $1-17 \%$ & Gazdar, 1988 \\
Sinaptofisina & $43-88 \%$ & $10-28 \%$ & Gazdar, 1988 \\
Leu-7 & $59-89 \%$ & $16-44 \%$ & Gazdar, 1988 \\
\hline
\end{tabular}

crovilos ou microácinos) ou neuroendócrina. SCC, independente do subtipo, apresentam núcleo redondo ou oval com cromatina finamente dispersa, citoplasma escasso $e$ organelas esparsas. Desmossomos podem ser identificados. Dentro dos processos citoplasmáticos, pequenos grânulos neurossecretórios podem ser identificados. Esses tumores diferem dos carcinóides pela presença nestes de maior número de grânulos neurossecretórios ${ }^{(24-25)}$.

\section{Morfometria}

A morfometria tem-se mostrado ferramenta útil na determinação de fatores morfológicos de prognóstico em câncer de pulmão, em parte por minimizar a subjetividade dos sistemas classificatórios, em parte por permitir a construção de modelos matemáticos preditivos de sobrevida(24-27). Assim, no carcinoma de células escamosas, o subtipo histológico mais freqüente de câncer de pulmão, que tem na ressecção cirúrgica o método ideal de tratamento, é sabido que, apesar do estadiamento ainda ser importante na determinação da sobrevida, pacientes com doença localizada apresentam recidivas nos primeiros cinco anos após ressecção cirúrgica. Para identificar quais seriam esses pacientes, foram estudados marcadores morfológicos de espécimes cirúrgicos relevantes para compor um modelo matemático em prever sobrevida. Assim, da análise histológica do espécimen, células tumorais exibindo relação núcleo/citoplasmática ou volume nuclear altos apresentaram melhor sobrevida. Esses resultados sugerem que a constatação inversa dos mesmos parâmetros poderiam selecionar os pacientes candidatos a modalidades terapêuticas complementares para evitar a recidiva tumoral(27). Essa sugestão foi reforçada pelos resultados obtidos nos carcinomas de células escamosas avançados pelo mesmo método. Neste estudo, constatamos que tumores apresentando células com relação núcleo/citoplasma e volumes nucleares baixos tiveram melhor comportamento em termos de sobrevida dos pacientes, possivelmente por melhor efeito radioterápico sobre as células assim caracterizadas ${ }^{(28,29)}$. Dando prosseguimento ao estudo, outro trabalho foi concebido para avaliar o papel de parâmetros clínicos e morfométricos em discriminar resposta à quimioterapia em pacientes com carcinomas de pequenas células do pulmão. Os resultados obtidos mostraram que volume dos núcleos e angiogênese tumorais foram as variáveis morfométricas mais relevantes para separar os dois grupos de pacientes, conferindo sensibilidade de $80,43 \%$ ao modelo. Concluiu-se, pelos resultados obtidos, que parâmetros histopatológicos podem fornecer informações valiosas quanto ao grau de resposta dos tumores à quimioterapia em pacientes com carcinomas de pequenas células do pulmão, encorajando o uso de procedimentos morfométricos na análise destes tumores ${ }^{(29)}$. 


\section{Fatores proliferativos}

As regiões organizadoras do nucléolo (NORs) são constituídas por segmentos de DNA que contêm os genes para a produção do ácido ribonucléico ribossômico (RNAr) e representam os nucléolos celulares. Usando-se uma técnica de impregnação com a prata, essas estruturas são visualizadas à microscopia óptica como pontos escuros (AgNOR). O número e a área de NORs no núcleo são relacionados com a síntese de proteínas e, portanto, as NORs expressam-se mais nos tumores de alto grau. Recentemente, Antonângelo et al. ${ }^{(10)}$ demonstraram que pacientes com carcinomas de células escamosas com baixa expressão de AgNOR apresentam maior sobrevida quando comparados com aqueles com tumores com alta expressão. Protocolos terapêuticos atualmente existentes dependem do estadiamento e da caracterização histológica do câncer de pulmão. Daí verifica-se a importância de um sistema de classificação no reconhecimento dos vários tipos histológicos. A classificação universalmente aceita como padrão de referência é a da Organização Mundial de Saúde (WHO, 1982), que se baseia em dados obtidos a partir da microscopia de luz. Essa classificação reconhece quatro tipos maiores de câncer de pulmão: carcinoma de células escamosas (epidermóide), carcinoma de células pequenas (oat-cell), adenocarcinoma, carcinoma de grandes células (anaplásico). Além de toda subjetividade, pertinente a qualquer sistema classificatório, outro grande problema a levar em conta diz respeito à representatividade do material. Em grande número de casos, esse evento possibilita apenas que neoplasias sejam grosseiramente separadas em oat-cell e não oat-cell, por exemplo. A experiência adquirida com o estudo de fatores de prognóstico no câncer de pulmão por Capelozzi et al. ${ }^{(21-24)}$ faltava ainda ser completada pela demonstração da utilidade da morfometria e histoquímica na rotina diagnóstica. Essa demonstração pode ser alcançada aplicando as mesmas técnicas em uma série diferente de tumores, proveniente de outro centro de estudo. Essa idéia resultou em trabalho, no qual o objetivo em questão era verificar o papel do AgNOR no comportamento dos carcinomas de células não-pequenas de pulmão operados, através da expressão nas células do tumor primário e metástases linfonodais. O estudo mostrou-nos que a expressão do AgNOR é útil em prever comportamento de carcinomas de células não-pequenas em estádio precoce (I e II). O estudo mostrou também que não há diferenças na expressão entre os tumores primários e metásticos, sugerindo que mecanismos de atividade proliferativa da célula tumoral no câncer de pulmão podem não ter influências nas metástases ${ }^{(30)}$.

\section{Ploidia celular (DNA)}

Há muitas controvérsias na literatura para o estudo da ploidia celular nos tumores de pulmão. Em estudo recen- te, Bernardi et al. ${ }^{(31)}$ demonstraram que carcinomas de células escamosas aneuplóides apresentaram menor sobrevida que os tumores diplóides/tetraplóides. Contudo, no mesmo trabalho, quando se incluíram no estudo outros marcadores de prognóstico, apenas a expressão das proteínas nucleolares (NORs) manteve correlação com a sobrevida.

\section{Biologia molecular}

O câncer de pulmão é tido atualmente como uma doença de bases genéticas. Uma variedade de experimentos recentes conduz inexoravelmente à conclusão de que as células cancerosas do pulmão acumulam uma série de alterações genéticas ("eventos iniciantes") que ativam proto-oncogenes (dominantes - famílias myc e ras) de um lado, enquanto uma série de outras alterações parece inativar ou perder informações de uma segunda classe de genes, referidos como genes de deleção ou genes supressores tumorais (recessivos-P53). Alterações em ambos os tipos de genes parecem ser necessárias para a transformação de células epiteliais brônquicas em células malignas cancerosas do pulmão. Com o conhecimento atual das bases genéticas do câncer de pulmão é possível colocar a broncoscopia como a primeira oportunidade de detectar anormalidades na biologia molecular do câncer de pulmão. De todos os estudos reportados até o momento, em 18 a $31 \%$ dos tumores de pacientes com SCC detectou-se amplificação de um membro da família myc dos proto-oncogenes ${ }^{(32,33)}$. Oito a $20 \%$ dos tumores NSCC também apresentam amplificação do myc. É improvável que a amplificação do myc seja um evento primário na patogênese do câncer de pulmão. A amplificação desses genes pode potencializar o crescimento de uma célula transformada, que poderá então formar a população dominante. A amplificação de genes da família myc tem sido associada a menor sobrevida em pacientes com $\mathrm{SCC}^{(34)}$. Os genes da família ras encontram-se mutáveis em 20 a $30 \%$ dos NSCC, enquanto nenhum dos 55 SCC estudados teve mutações ${ }^{(35)}$. As mutações são mais comumente encontradas em adenocarcinomas (24\%) do que em carcinomas de células escamosas $(8 \%)^{(34,35)}$. Em adição, o estudo do câncer de pulmão tem permitido identificar alterações genéticas especificamente associadas aos tipos histológicos. A incidência de mutação do ras nos carcinomas de grandes células é de $23 \%$, predominando em adenocarcinomas do pulmão, enquanto anormalidades no gene retinoblastoma são mais comuns nos SCC. As mutações observadas no câncer de pulmão associado ao fumo, tanto no lócus K-ras quanto no lócus p53, têm sido atribuídas a uma transgressão nas bases glicina para timidina, enquanto alterações em outros tumores, predominantemente gastrointestinais, têm sido atribuídas a transgressões nas bases guanidina. A identificação de 
mutações nos genes K-ras em NSCC tem sido associada com menor sobrevida dos pacientes ${ }^{(36)}$. Mutações do gene p53 têm sido encontradas em 77 a $100 \%$ dos SCC e também em 49 a $74 \%$ dos NSCC. As anormalidades no P53 podem ser em lesões pré-invasivas, câncer precoce e em $7 \%$ das alterações metaplásicas no epitélio brônquico. A expressão dos genes myc, ras e p53 pode ser detectada por simples métodos imuno-histoquímicos.

\section{MARCADORES BIOLÓGICOS INTERMEDIÁRIOS - DETECÇÃO PRECOCE DO CÂNCER}

\section{ESCARRO, RADIOGRAFIA E TOMOGRAFIA COMPUTADORIZADA}

É bem conhecida a alta morbidade e mortalidade do câncer de pulmão, o que torna esta doença significante problema de saúde pública, mesmo com os avanços recentes ocorridos no tratamento.

Causas importantes para a permanência de altos índices de mortalidade são o potencial agressivo destas neoplasias, o diagnóstico em estádios avançados e a ausência de métodos eficazes para o diagnóstico precoce, principalmente nos indivíduos de alto risco.

Até o momento, a radiografia de tórax de rotina e a citologia oncótica do escarro fazem parte dos exames mais utilizados para selecionar os pacientes de alto risco.

Outro método que vem sendo sugerido por alguns autores para o diagnóstico precoce dos carcinomas de pulmão é a tomografia computadorizada na detecção de tumores pequenos, mostrando-se 600 vezes superior à radiografia, porém ainda não completamente aceita na prática pela ausência de estudos não-randomizados $e$ alto custo para grandes populações.

\section{BiOLOGIA MOLECULAR}

Estudos moleculares recentes sobre a biologia do processo carcinogênico em tumores sólidos humanos têm sugerido novas abordagens para o diagnóstico precoce dessas patologias. Esses novos conceitos baseiam-se no fato de que a carcinogênese ocorre após mutações progressivas em células pré-malignas, que posteriormente evoluem para o tumor invasivo e metastático.

Anormalidades morfológicas pré-malignas no epitélio brônquico de pacientes com alto risco para neoplasias pulmonares já foram descritas já em $1957^{(37)}$ e complementadas por trabalhos atuais, em que anormalidades genéticas e epigenéticas associadas a essas alterações histopatológicas vêm sendo estudadas, com vistas a ser utilizadas como biomarcadores para detecção precoce de transformação celular(38).

\section{Anormalidades epigenéticas - Teste da metilação}

Entre as anormalidades epigenéticas, a metilação de promotores gênicos tem sido reconhecida como um efi- ciente mecanismo de supressão gênica, especialmente dos genes CDKN2A (p16) e MGMT, presentes em 100\% dos pacientes com carcinomas de células escamosas e, portanto, classificando tal teste como excelente estratégia para triagem em escarro, porém limitado aos grandes laboratórios pela necessidade de ensaios de PCR de alta sensibilidade, o que não é viável para muitos.

Anormalidades genéticas - Amplificações, deleções de alelo, mutações

Dentre as anormalidades genéticas, amplificações gênicas, deleções de alelo e mutações de ponto têm sido as mais comumente descritas em carcinomas pulmonares ${ }^{(38)}$.

As amplificações gênicas, por exemplo do HER-2/neu, são mais comumente associadas com estádios clínicos mais avançados ${ }^{(39)} e$, portanto, não são úteis como biomarcadores precoces. Do mesmo modo, as mutações de ponto, embora sejam freqüentes nos carcinomas invasivos, têm sido raramente observadas em lesões pré-malignas e em epitélio brônquico normal de fumantes ${ }^{(40)}$. A mutação em p53, por exemplo, foi detectada em 33 a $70 \%$ dos carcinomas pulmonares invasivos; entretanto, é raramente descrita em lesões pré-malignas(41) ou na mucosa brônquica de fumantes sem evidência de tumor de pulmão(42).

A deleção de alelos, um fenômeno comumente documentado pela perda de heterozigose ( $\mathrm{PH})$, tem sido demonstrada tanto nos tumores invasivos quanto nas lesões pré-neoplásicas. Essas deleções podem ocasionar a perda de genes supressores tumorais e com isso favorecer o desenvolvimento de neoplasias ${ }^{(43)}$. Algumas regiões cromossômicas, como os braços curtos dos cromossomos 3 , 9 e 17, têm sido mais freqüentemente afetadas por deficiências nos tumores pulmonares. Nessas regiões estão localizados importantes genes relacionados com origem e progressão em cânceres humanos, como os genes FHIT (3p14.2, 44), WNT7a (3p25) e B-catenin (3p21.3, 45), o gene CDKN2A/p16 (9p21) e o gene TP53 em 17p13. Este último é o supressor tumoral mais comum nos cânceres humanos $^{(38)}$. Mao et al. ${ }^{(38)}$ demonstraram PH nas três regiões cromossômicas supracitadas também em epitélio brônquico normal de indivíduos fumantes.

Anormalidades cromossômicas - Aneuploidias, deleções

Além das alterações encontradas no nível genético, alterações numéricas como perdas ou ganhos de cromossomos também têm sido descritas nas neoplasias pulmonares e em lesões pré-malignas. Alterações cromossômicas numéricas ou aneuploidias ${ }^{(38)}$ são conhecidas desde o início dos anos 80 , tendo sido amplamente estudadas com o advento da citometria de fluxo para detectar aneuploidias e estabelecer suas correlações prognósticas. Evidências recentes sugerem que a aneuploidia reflete $a$ instabi- 
lidade cromossômica nas células tumorais, característica dos tumores de pulmão.

Alterações cromossômicas como aneuploidias e deleções podem ser detectadas em células interfásicas através de ensaios de hibridização in situ com sondas de DNA marcadas por imunofluorescência, um teste designado como FISH. Este teste tem sido usado rotineiramente em laboratórios de patologia molecular e de citogenética clínica.

\section{MÉTODOS PARA DETECÇÃO DE ANORMALIDADES CROMOSSÔ- MICAS}

Dentre os vários métodos para diagnóstico das anormalidades cromossômicas estão o clássico bandeamento cromossômico, cariótipo espectral (SKY) e o FISH interfásico. Técnicas clássicas apresentam dificuldades: cultivo das células de tumores pulmonares sólidos in vitro pode reduzir número de metáfases disponíveis, inviabilizando a análise; outras limitações: baixo índice mitótico, morfologia cromossômica de baixa qualidade, alta heterogeneidade e complexidade dos arranjos cromossômicos. As novas técnicas de cariótipo molecular, como o SKY, estão-se destacando como um excelente método para pesquisá-las, não só em células tumorais como em epitélio normal ou em lesões pré-malignas de indivíduos fumantes.

\section{Cariótipo espectral (SKY)}

O cariótipo espectral ou SKY é um método de hibridização semelhante ao FISH, mas que utiliza um conjunto de sondas DNA que cobrem os 22 pares de autossomos e os cromossomos sexuais $\mathrm{X}$ e $\mathrm{Y}$. As sondas específicas para cada cromossomo são marcadas com um fluorocromo ou uma mistura de vários fluorocromos. Após a hibridização, um filtro de interferência especial conjugado a um sistema computadorizado com software próprio captura a imagem da metáfase e transforma os múltiplos perfis espectrais em cores, de forma que cada cromossomo é "pintado" de uma cor diferente. O SKY, portanto, permite que, na avaliação de uma única célula, todos os cromossomos sejam estudados conjuntamente.

\section{FISH interfásico}

O FISH em células interfásicas, da mesma forma que o SKY, utiliza sondas com seqüencias de DNA complementares às seqüências que se deseja estudar, exceto que tais seqüências são específicas para genes ou regiões cromossômicas. As sondas são marcadas com fluorocromos para permitir visualização no microscópio de fluorescência. A desvantagem do FISH é que, como sonda específica, é necessário conhecer o que se deseja estudar para escolher as sondas que serão específicas apenas para detectar tais alterações.

\section{Anormalidades detectadas pelo FISH e SKY}

Os métodos de hibridização in situ, como o FISH e o SKY, permitem identificar tanto as anormalidades cromossômicas numéricas, como as monossomias e trissomias, quanto estruturais, como as deleções e translocações. Assim, por exemplo, tanto nas leucemias, quanto nos tumores sólidos, esses métodos têm-se mostrado mais sensíveis que a citogenética clássica.

Várias anormalidades já foram documentadas nos carcinomas pulmonares. A deleção do braço curto do cromossomo 3 foi detectada por FISH no carcinoma de pequenas células do pulmão e no epitélio brônquico de fumantes antes do aparecimento do câncer ${ }^{(46)}$. Aneuploidia nos cromossomos 6, 7, 8, 9, 12, 17, 18 e Y também pode ser detectada pelo método do FISH em carcinomas, assim como cópias extras: polissomias do 7, 6, 12 e 17 .

\section{CONCLUSÕES - PERSPECTIVAS FUTURAS}

Apesar do conjunto de anormalidades citogenéticomoleculares observadas nas neoplasias pulmonares, não existem ainda testes citogenéticos para uso clínico no diagnóstico, por vários motivos: ausência de única alteração comum a todos tipos de tumores ou grupo morfológico específico, heterogeneidade do trato respiratório e alterações presentes de forma focal, em que o escarro pode compensar, pois inclui células representativas de diversas áreas.

O FISH interfásico foi usado com sucesso na detecção do carcinoma de bexiga, através de um painel com quatro sondas de DNA, incluindo os cromossomos 3, 7 e 17 e seqüências do gene p16 em 9p2. Verificadas a sensibilidade e a especificidade desse painel nas células isoladas de urina, ele foi aplicado em mais de 200 pacientes, com sensibilidade do FISH maior que a citologia para detecção do carcinoma urotelial.

No futuro, espera-se desenvolver um painel de sondas para detecção de câncer de pulmão em ensaio de FISH interfásico.

\section{REFERÊNCIAS}

1. Landis SH, Murray T, Bolden S, Wing PA. Cancer Stat 1998;48:1229.

2. Brasil. Ministério da Saúde. Estimativa da incidência e mortalidade por câncer no Brasil. Rio de Janeiro: INCA/PRO-ONCO, 1998.

3. Ginsberg RJ, Vokes EE, Raben A. Cancer of the lung. In: Devita JR, et al, eds. Cancer: principles and practices of oncology. $5^{\text {th }}$ ed. Philadelphia: Lippincott-Raven, 1997;658-677.

4. Anelli A. Quimioterapia em câncer de pulmão de pequenas células. In: Younes RN, ed. Tumores torácicos. 1ạ ed. Rio de Janeiro: MEDSI, 1997;269-280.

5. Seregni E, Botti A, Bogni E, Bombardieri E. Tumour marker evaluation in patients with lung cancer. Scand J Clin Lab Invest 1995;55 (Supl 221):67-71.

6. Younes RN. Lung cancer: role of surgery in the treatment of non-small cell lung cancer stages I, II and III. South Am J Cancer 1997;1:153. 
7. Mountain $\mathrm{CF}$. Revisions in the international system for staging lung cancer. Chest 1997;111:1710-1717.

8. Naruke T, Tsuchiya R, Kondo H, Asamura H, Nakayama H. Implications of staging lung cancer. Chest 1997;112:S242-248.

9. Johnson DH, Marangos PJ, Forbes JT. Potential utility of serum neuron-specific enolase level in small cell carcinoma of the lung. Cancer Res 1984;44:5409-5414

10. Antonangelo L, Bernardi FDC, Capelozzi VL, Takagaki T, Younes RN, Saldiva PH. Morphometric evaluation of argyrophilic nucleolar organizer region in predicting long-term survival in squamous cell carcinoma of the lung. Chest 1997;111:110-114

11. Barbuto JAM. Marcadores tumorais. In: Rentani MM, Coelho RG, Iyeasu H, Kowalski LP, eds. Bases da oncologia. 1a ed. São Paulo: Lemar, 1998;351-374.

12. Schwartz MK. Cancer markers. In: De Vita JR, Hellman S, Rosemberg AS, eds. Cancer: principles and practices of oncology. $4^{\text {th }}$ ed. Philadelphia: Lippincott-Raven, 1993;531-542.

13. Bagashawe KD, Rustin GJS. Circulating tumor markers. In: Perkhan $\mathrm{M}$, Pinedo $\mathrm{H}$, Veronesi U, eds. Oxford textbook of oncology. $1^{\text {st }}$ ed. Oxford: Oxford University Press, 1995;412-419.

14. Coombes RC, Dearnaley NP, Ellison ML, Neville AM. Markers in breast and lung cancer. Ann Clin Biochem 1982;19:263-268.

15. Gail MH, Eagan RT, Feld R, et al. Prognostic factors in patients with resected stage I non-small cell lung cancer: a report of lung cancer study group. Cancer 1984;54:1802-1813.

16. Takagaki TY. Marcadores tumorais em carcinoma broncogênico [tese] São Paulo: Faculdade de Medicina, Universidade de São Paulo, 1992; 83p.

17. Gross JL. Marcadores tumorais séricos em pacientes com carcinoma de pulmão não pequenas células [dissertação]. São Paulo: Faculdade de Medicina, Universidade de São Paulo, 1999;103p.

18. Gazdar AF, Helman LJ, Israel MA, et al. Expression of neuroendocrine cell markers 1-dopa decarboxylase, chromogranin $\mathrm{A}$, and dense core granules in human tumors of endocrine and nonendocrine origin. Cancer Res 1988;48:4078-4082.

19. Graziano SL, Mazid L, Newman N, et al. The use of neuroendocrine immunoperoxidase markers to predict chemotherapy response in patients with non-small-cell lung cancer. J Clin Oncol 1989;7:1398-1406.

20. Jorgensen L, Hirsch FR, Skov BG, Osterlind K, Cooper EH, Larsson LI. Occurrence of neuron specific enolase in tumour tissue and serum in small cell lung cancer. Br J Cancer 1991;63:151-153.

21. Delmonte Capelozzi V, Alberti O, Saldiva PH. Large cell carcinoma of the lung. Ultrastructural and immunohistochemical features. Chest 1986;90:524-527.

22. Delmonte Capelozzi V. Câncer de pulmão. Oncogênese. J Pneumol 1987; 13:35-50

23. Capelozzi VL, Sheppard MN, Saldiva PHN. Modeling survival in neuroendocrine lung tumors based on clinical and morphometric data. Chest 1994;106(Suppl):76S

24. Capelozzi VL, Dewar A, Saldiva PHN, Sheppard MN. Morphometric characterization of typical carcinoid, atypical carcinoid, large cell neuroendocrine carcinoma and small cell carcinoma of the lung based on ultrastructural and stereological procedure. Chest 1994;106(Suppl): 90S.

25. Battlehner CN, Saldiva PHN, Carvalho CRR, Takagaki TY, Montes GS, Younes RN, et al. Nuclear/cytoplasmic ratio correlates strongly with survival in non-disseminated neuroendocrine carcinoma of the lung. Histopathology 1993;22:31-34.

26. Delmonte Capelozzi V, Battlehner CN, Montes GS, Saldiva PHN. Volume fraction of dense-core granules correlates well with survival in disseminated (stage IV) neuroendocrine carcinoma of the lung. Pathol Res Pract 1993;189:1145-1148.

27. Bernardi FDC, Capelozzi VL, Takagaki T, Younes R, Saldiva PHN Usefulness of morphometric evaluation of histopathological slides is useful in predicting long-term outcome of patients with squamous cell carcinoma of the lung. A preliminary report. Chest 1995;107:614620

28. Carvalho HA, Takagaki TH, Saldiva PHN, Capelozzi VL. Stereological estimates of nucleus/cytoplasm ratio and star volume on fiber-optic biopsies are of prognostic value to discriminate survival after radiotherapy in advanced squamous cell carcinoma of the lung. Histopathology 1997;31:420-429.

29. Caporrino C, Saldiva PHN, Farhat CA, Takagaki TY, Younes RY, Capelozzi VL. Stereological estimates of nuclear star volume and vessels as predictors of chemotherapy response in small cell carcinoma of the lung. Histopathology 1999;35:257-266.

30. Rodrigues OR, Antonangelo L, Franco Filho EC, Capelozzi VL, Saldiva PHN. Prognostic significance of argyrophilic nucleolar organizer region (AgNOR) staining in mediastinal lymph nodes metastasis and resected non-small cell lung cancer. J Jpn Assoc Thorac Surg 1996; 44(Suppl):260-264

31. Bernardi FDC, Antonângelo L, Beyruti R, Takagaki T, Saldiva PHN, Capelozzi VL. Clinical, pathological and biological markers of prognosis in surgically resected squamous cell carcinoma of the lung. Mod Pathol 1997; 10:992-1000.

32. Noguchi M, Hirohashi S, Hara F, et al. Heterogeneous amplification of myc family oncogens in small cell lung cancer. Cancer 1990;66:20532059.

33. Mitsudomi T, Oyama T, Kusano T, Osaki T, Nakanishi R, Shirakusa T. Mutations of the p53 gene as a predictor of poor prognosis in patients with non-small cell lung cancer. J Natl Cancer Inst 1993;85:20182023.

34. Demarchi LMMF, Reios MM, Palomino SAP, et al. Prognostic values of stroma proportion and PCNA, K67 and p53 proteins in patients with resected adenocarcinoma of the lung. Mod Pathol 2000;13:511520 .

35. Carvalho PEO, Antonângelo L, Bernardi FDC, Leão LEV, Rodrigues $\mathrm{RO}$, Capelozzi VL. Useful prognostic panel makers to express the biological tumor status in resected lung adenocarcinomas. Jpn J Clin Oncol 2000;30:478-486

36. Slebos RJC, Kibblelaar RE, Dalesio O, et al. K-ras oncogene activation as a prognostic marker in adenocarcinoma in the lung. $\mathrm{N}$ Engl $\mathrm{J}$ Med 1990;323:561-565.

37. Auerbach $\mathrm{O}$, Gere JB, Forman JB, et al. Changes in bronchial epithelium in relation to smoking and cancer of the lung. $\mathrm{N}$ Engl $\mathrm{J}$ Med 1957; 156:97-104

38. Mao L, Lee JS, Kurie JM, Fan YH, Lippman SM, Lee JJ, et al. Clonal genetic alterations in the lungs of current and formers smokers. J Natl Cancer Inst 1997;89:857-862

39. Schneider PM, Praeuer HW, Stoeltzing O, et al. Multiple molecular marker testing (p53, C-Ki-ras, c-erbB-2) improves estimation of prognosis in potentially curative resected non-small cell lung cancer. $\mathrm{Br} \mathrm{J}$ Cancer 2000;83:473-479.

40. Sozzi G, Miozzo M, Donghi R, Pilotti S, Cariani CT, Pastorino U, Della Porta G. Dellection of $17 \mathrm{p}$ and p53 mutations in the preneoplastic lesions of the lung. Cancer Res 1992;52:6079-6082.

41. Greenblant MS, Bennet WP, Hollstein M, Harris CC. Mutation in the p53 suppressor gene: clues to cancer etiology and molecular pathogenesis. Cancer Res 1994;43:5026-5032.

42. Franklin WA. Diagnosis of lung cancer. Pathology of invasive and preinvasive neoplasia. Chest 2000;117:80S-89S.

43. Dutrillaux B. Pathways of chromosome alteration in human epithelial cancers. Adv Cancer Res 1995;67:59-82.

44. Ohta M, Inoue H, Cotticelli MG, et al. The FHIT gene, spanning the chromosome 3p14 fragile site and renal carcinoma-associated $\mathrm{t}(3,8)$ breakpoint, is abnormal in digestive tract cancers. Cell 1996;84:587597.

45. Calvo R, West J, Franklin W, et al. Altered HOX and ENT7A expression in human lung cancer. PNAS USA 2000;97:12776-12781.

46. Halling KC, King W, Skolova IA, et al. A comparison of cytology and fluorescence in situ hybridization for the detection of urothelial carcinoma. J Urol 2000;164:1768-1775. 